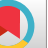

\title{
Association of Circulating Branched-Chain Amino Acids with Gestational Diabetes Mellitus: A Meta-Analysis
}

\author{
Liang Zhao ${ }^{1,2}$, Meng Wang ${ }^{1,3}$, Jun $\mathrm{Li}^{4}$, Ye $\mathrm{Bi}^{1}$, Minglong $\mathrm{Li}^{1,{ }^{*}}$ and Jie Yang ${ }^{2}$ \\ ${ }^{1}$ Department of Endocrinology, Shandong Provincial Hospital Affiliated to Shandong University, Jinan, China \\ ${ }^{2}$ The Second Department of Endocrinology, The Central Hospital of Taian, Taian, China \\ ${ }^{3}$ Department of Endocrinology, Yidu Central Hospital of Weifang, Weifang, China \\ ${ }^{4}$ Department of Anesthesiology, The Affiliated Hospital of Taishan Medical University, Taian, China \\ "Corresponding author: Department of Endocrinology, Shandong Provincial Hospital Affiliated to Shandong University, Jinan, China. Email: hei71mie@yeah.net
}

Received 2018 October 16; Revised 2019 May 14; Accepted 2019 May 25.

\begin{abstract}
Context: Recently, the relationship between branched-chain amino acids (BCAAs) and diabetes mellitus (DM) has attracted worldwide attention. However, the results related to plasma BCAAs concentrations and gestational diabetes mellitus (GDM) lack statistical power due to the small sample size of a single article.

Objectives: This study quantitatively summarized current observational studies to evaluate the association between plasma BCAAs concentration levels and GDM.

Methods: A systematic search was performed to select eligible publications using PubMed and EMBASE databases until July 23 , 2018. The references of relevant articles were also manually searched. The quality evaluation of included studies was according to the guidelines of the Newcastle-Ottawa Scale (NOS). Data were analyzed with Review Manager 5.3 and STATA 14.0 software. In total, seven articles (including eight studies) involving 432 subjects were included.

Results: The results showed that all three-individual plasma BCAAs concentration levels in the GDM group were higher than those in the control group (leucine: SMD = 3.76, 95\% CI: 1.70 - 5.82, P (SMD) < 0.001; isoleucine: SMD = 3.15, 95\% CI: 1.42 - 4.87, P (SMD) < 0.001 ; valine: $\mathrm{SMD}=2.77,95 \% \mathrm{CI}: 1.21$ - 4.32, $\mathrm{P}(\mathrm{SMD})=0.001)$, and the differences were statistically significant. In addition, subgroup analysis indicated that age, body mass index (BMI), publication year, and ethnicity were positively associated with plasma BCAAs
\end{abstract} concentrations in GDM.

Conclusions: Plasma BCAAs, as potential biomarkers, might be associated with GDM risk, which provides useful information for the prevention and early diagnosis of GDM.

Keywords: Circulating, Branched-Chain Amino Acids (BCAAs), Gestational Diabetes Mellitus (GDM), Meta-Analysis

\section{Context}

The increasing prevalence of diabetes mellitus (DM) is a serious public health issue worldwide, causing significant morbidity and mortality $(1,2)$. Approximately 415 million people aged 20 to 79 suffered from DM worldwide in 2015, and the prevalence of cases is expected to increase substantially in the coming decades (3). The number of patients is projected to rise to 592 million by 2030, bringing with it debilitating and costly consequences, including retinopathy, cardiovascular disease, kidney dysfunction, etc. (4). Among all types of DM, gestational diabetes mellitus (GDM) could be especially difficult on women because it may be a bigger threat to the women. Furthermore, GDM is diabetes that is first diagnosed in the second or third trimester of pregnancy and is not clearly pre-existing type 1 or type 2 diabetes (5). Gestational diabetes mellitus can cause unique difficulties (e.g., miscarriage, birth defect, preeclampsia heart attack, female sexual dysfunction, etc.) (6-8). These findings highlight the necessity to find effective therapies to prevent and treat DM.

Branched-chain amino acids (BCAAs), consisting of leucine, isoleucine, and valine, are essential amino acids that cannot be made by the body, and must be primarily obtained from the diet (9). Abnormal plasma BCAAs concentrations were associated with metabolic disease and several pathological states, such as obesity, metabolic syndrome, liver disease, chronic kidney disease, DM, etc. (1012). Recently, the relationship between BCAAs and DM has attracted worldwide attention. Several studies found GDM have elevated plasma amino acids, especially BCAAs (13-16), while others reported that they were within normal ranges (17-19). Furthermore, the results related to plasma BCAAs 
concentrations and GDM lack statistical power due to the small sample size of a single article.

\section{Objectives}

Therefore, the researchers conducted the metaanalysis to further investigate the association between plasma BCAAs concentrations and GDM.

\section{Methods}

\subsection{Search Strategy}

This meta-analysis was reported in accordance with the PRISMA Statement (20). Comprehensive literature search was performed in the PubMed and EMBASE databases to retrieve potential eligible studies for meta-analysis and the cut-off date was up to July 23, 2018. The researchers used the following combined keywords and MeSH terms, and the retrieval strategy of (((mellitus [Title/Abstract]) OR GDM [Title/Abstract]) OR glycuresis [Title/Abstract]) OR diabetes mellitus [Title/Abstract]) AND (((((branched chain amino acids [Title/Abstract]) OR BCAAs [Title/Abstract]) OR valine [Title/Abstract]) OR leucine [Title/Abstract]) OR isoleucine [Title/Abstract]). References cited in the retrieved articles were also reviewed to identify additional eligible studies.

\subsection{Inclusion and Exclusion Criteria}

Inclusion criteria for the eligible studies included: (1) case-control or cohort studies design, comparing the concentrations levels of BCAAs in blood, serum, and plasma in patients with GDM and controls (healthy pregnant women); and (2) published in English with the full-text article available. Exclusion criteria for the articles included: (1) duplicated publications, (2) letters, reviews, meta-analysis, case reports, expert opinions, and abstracts, and studies that did not meet the above inclusion criteria were excluded.

\subsection{Data Extraction and Quality Assessment}

The information from all eligible studies was independently evaluated by two investigators. A third person resolved the differences until all reached a set of similar statements. The following information was extracted from each eligible study: Name of the first author, year of publication, ethnicity, number of participants, demographic characteristics (e.g. number, age and body mass index (BMI)) of case and control groups, mean and standard deviation (SD) or median and quartiles of three individual or total plasma BCAAs concentrations levels in both the patients and controls.

\subsection{Quality Assessment}

The methodological quality assessment of the included study was independently conducted by two investigators according to the guidelines of the Newcastle-Ottawa Scale (NOS). This scale uses a star system (with a maximum of nine stars), which is composed of three domains (21): Selection of participants (including four items), comparability of study groups (including two items), and the ascertainment of exposure or outcome (including three items), which are used to judge the applicability and risk of bias (22). Each question was answered with "yes", "no", or "unclear". A "yes" answer represents the low-risk of bias and is assigned a score of one, while a "no" or "unclear" answer represents a high-risk of bias and is assigned a score of zero. Thus, the quality score of studies ranged from zero to nine stars. Higher scores were a reflection of lower risk of bias (22). Studies that scored seven stars or greater than seven stars were regarded as lower risk of bias, and those scored less than seven stars indicated higher or moderate risk.

\subsection{Statistical Analysis}

Meta-analysis was conducted using STATA 14.0 (Stata Corporation: College Station, TX, USA) and Review Manager 5.3 (Copenhagen: Nordic Cochrane Centre, the Cochrane Collaboration, 2014) software. Considering that the included studies used different measurement methods with various units for the same indicator variable, the researchers pooled the standardized mean difference (SMD) and their 95\% confidence intervals (CIs) to detect the effect size between the two groups. Heterogeneity among studies was assessed using Cochran Q test and I-squared $\left(\mathrm{I}^{2}\right)$ statistics index. A P value of the $\chi^{2}$ based Cochran $\mathrm{Q}$ test less than 0.1 or $\mathrm{I}^{2}$ index greater than $50 \%$ suggested the existence of overall statistically significant heterogeneity and the utilization of a random-effect model. Otherwise, a fixed-effect model was used (23). The stratified analyses based on age, BMI, and ethnicity were conducted on those comprising of two or more studies. Sensitivity analyses were performed by excluding one study at a time and recalculating the effect size. Moreover, publication bias was detected using the Egger's test (24). Two-sided P value less than 0.05 was considered statistically significant.

\section{Results}

\subsection{Eligible Studies}

Initially, 3041 potentially relevant articles from electronic databases and other sources were searched, of which 727 duplications and 2239 irrelevant articles were excluded. After full-text review of retained candidate articles, 
68 potential studies were further excluded because of failure to accord with the inclusive criteria. Finally, seven eligible articles (13-18) including eight studies with 432 subjects were included in the meta-analysis (Figure 1). Among these articles, only one article focused on isoleucine and valine, and six articles (including seven studies) reported BCAAs. Thus, six articles with seven studies examined circulating leucine concentrations levels, and seven articles (including eight studies) detected circulating isoleucine and valine concentrations levels.

\subsection{Study Characteristics and Quality Assessment}

As shown in Table 1, Metzger et al. (14) studied the role of BCAAs in two independent research samples, which were regarded as two independent studies and included in this meta-analysis. Thus, seven articles including eight studies covering 229 patients and 203 controls were published from 1980 to 2018 . All studies were case-control studies. Studies were carried out in Sweden, Canada, Iran, Korea, Greece, Italy, and USA. The mean age of patients ranged from 27.0 to 38.6 years, and the mean BMI ranged from 25.70 to $30.43 \mathrm{~kg} / \mathrm{m}^{2}$. The methodological quality of each study was evaluated using NOS. Each study received moderate or high quality with scores between seven and nine, as exhibited in Table 1.

\subsection{Overall Meta-Analysis}

As indicated in Figure 2, the concentration levels of circulating leucine (SMD: 3.76, 95\% CI: 1.70 to 5.82, P (SMD) < 0.001), isoleucine (SMD: 3.15, 95\% CI: 1.42 to 4.87, P (SMD) < 0.001 ), and valine (SMD: $2.77,95 \% \mathrm{CI}: 1.21$ to $4.32, \mathrm{P}$ (SMD) $=$ 0.001 ) in patients were significantly increased. Nevertheless, high heterogeneity $\left(\mathrm{I}^{2}>96.0 \%\right)$ emerged among the included studies.

\subsection{Stratified Analysis and Sensitivity Analysis}

To explore the sources of heterogeneity, stratified analysis based on age ( $<30$ vs. $\geq 30$ ), BMI ( $<28$ vs. $\geq 28$ ), year of studies (2005 and lower vs. 2007 and higher), and ethnicity (Asian vs. Caucasian) were performed. As summarized in Table 2, the results suggested that age, BMI, and ethnicity were positively associated with plasma BCAAs levels in the patients. Although heterogeneity was reduced in the mean age of $<30$ years, mean BMI $\geq 28 \mathrm{~kg} / \mathrm{m}^{2}$, publication year $<2007$ and Asian groups, dramatic heterogeneity persisted in the other groups. Considering the existence of heterogeneity in the current study, the researchers performed sensitivity analysis, and removed any of the included studies that had no significant impact on the metaanalysis outcomes, suggesting that the results were stable (Figure 3).

\subsection{Publication Bias}

Egger's test was applied to assess the potential publication bias in the included studies. Funnel plots for leucine $(\mathrm{P}=0.066)$, isoleucine $(\mathrm{P}=0.083)$, and valine $(\mathrm{P}=0.080)$ showed that potential publication bias risk may exist in the meta-analysis.

\section{Discussion}

The current study showed that the increase of individual plasma BCAAs concentration may be related to the increased risk of GDM, however, the heterogeneity between different studies was relatively high, and the researchers used subgroup analysis to find the reasons for the heterogeneity.

Recently, the plasma BCAAs as biomarkers for DM patients has gained much attention (12). The complex association between diabetes and branched-chain amino acids was not fully understood (25). Accumulating evidences demonstrates that their abnormal concentrations associated with various DM, such as type 2 diabetes mellitus (T2DM) and GDM (26-29). More importantly, plasma BCAAs are extremely stable and present in serum, plasma, urine, milk, etc. $(26,30-32)$. Moreover, the use of plasma BCAAs is less invasive and less traumatic to the subjects. Furthermore, one hypothesis involves a mammalian Target of Rapamycin Complex 1(mTORC1) that is activated by BCAA and activated by insulin and glucose by cellular ATP availability (33). If this is a relevant pathway, BCAA overload may cause insulin resistance by activating the mammalian target of rapamycin (mTOR) and lead to an increase in acylcarnitine $(25,34)$. Therefore, BCCAs may be potential biomarkers of GDM and plasma BCAAs can be served as reliable biomarkers for prevention, early diagnosis, and treatment of diabetes. In this study, the researchers demonstrated that plasma BCAAs are elevated in GDM patients, which are promising biomarkers for prevention, early detection, and treatment of GDM.

Among these diabetes-related metabolites, BCAAs are the most frequently studied metabolites (28). Dysregulation of plasma BCAAs was observed in multiple diseases, including GDM (16). Plasma BCAAs concentrations are different in different DM patients, which is useful to detect early DM (35), distinguish DM subtypes (16), and correlate with age, BMI, and ethnicity of patients $(36,37)$. The latest research suggests that normal or impaired glucose tolerance and T2DM groups have significant differences in BCAAs, and GDM has elevated plasma BCAAs (38). Additionally, similar results were found after BMI adjustment (38). However, Pappa et al. (18) documented that these significances disappeared, and BCAAs were within normal ranges in GDM patients. 


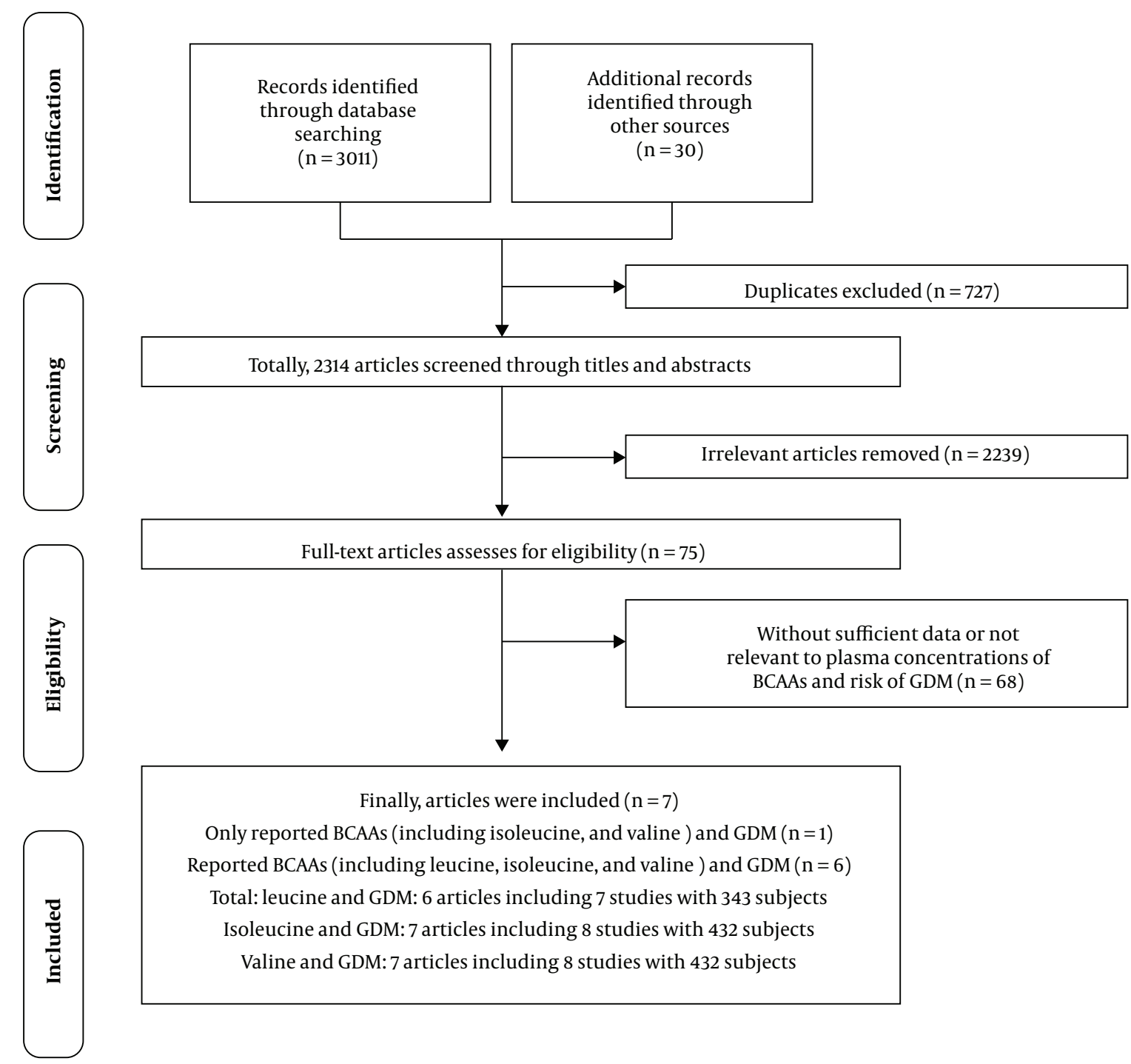

Figure 1. Procedures of selecting eligible studies

The above-mentioned studies demonstrated that plasma BCAAs might serve as wonderful biomarkers for GDM (12-15), yet others did not support these roles in GDM detection (16-18). Therefore, the current researchers further evaluated the relationship between plasma BCAAs and GDM, and found that all three individual plasma BCAA concentration levels in GDM group were higher than those in the control group (leucine: SMD $=3.76,95 \%$ CI:1.70 - 5.82, $\mathrm{P}(\mathrm{SMD})<0.001$; isoleucine: $\mathrm{SMD}=3.15,95 \% \mathrm{CI}: 1.42-4.87, \mathrm{P}$ (SMD) < 0.001; valine: SMD = 2.77, 95\% CI:1.21 - 4.32, P (SMD) $=0.001)$ and the difference was statistically significant. These three representative parameters confirmed that the elevated individual plasma BCAAs concentrations might be associated with increased GDM risk, which also proved that plasma BCAAs are promising predictors for examining GDM.

Plasma BCAA concentrations vary in different age groups, BMI groups, ethnicity groups, publication year group etc. Here, the researchers demonstrated that there were significant differences between the mean age $\geq 30$ years of GDM group and control group in terms of all three individual BCAAs, while these differences disappeared in the mean age of $<30$ years of GDM patients. In addition, the mean BMI of patients may influence BCAAs concen- 


\begin{tabular}{|c|c|c|c|c|c|c|c|c|c|c|c|}
\hline $\begin{array}{l}\text { Authors } \\
\text { (Ref.) }\end{array}$ & Year & Country & Ethnicity & Cases & Controls & Age $^{\mathbf{a}}, \mathrm{y}$ & $\mathrm{BMI}^{\mathrm{a}}, \mathrm{kg} / \mathrm{m}^{2}$ & Diagnostic Criteria for GDM & $\begin{array}{l}\text { Cases: BCAAs } \\
\text { Concentrations }{ }^{\mathrm{a}} \text {, } \\
\text { mmol/L }\end{array}$ & $\begin{array}{l}\text { Controls: BCAAs } \\
\text { Concentrations }{ }^{\mathbf{a}} \text {, } \\
\text { mmol/L }\end{array}$ & $\begin{array}{l}\text { NOS } \\
\text { Score }\end{array}$ \\
\hline $\begin{array}{l}\text { Roy et al. } \\
\text { (17) }\end{array}$ & 2018 & Canada & Caucasian & 50 & 50 & $\begin{array}{l}\text { Cases: } 31.00 \pm 3.80 \\
\text { Controls: } 31.00 \pm \\
3.70\end{array}$ & $\begin{array}{l}\text { Cases: } 25.70 \pm \\
5.40 ; \text { Controls: } \\
25.70 \pm 5.20\end{array}$ & $\begin{array}{l}\text { A GDM diagnosis was made if two } \\
\text { values (GCT and OGTT) exceeded } \\
\text { the thresholds. A GDM diagnosis } \\
\text { was also made if information in } \\
\text { the medical file indicated that } \\
\text { the participant had started } \\
\text { taking insulin during pregnancy } \\
\text { without undergoing an OGTT. }\end{array}$ & $\begin{array}{l}\text { Leucine: } 109.92 \pm \\
0.69 ; \text { Isoleucine: } \\
56.41 \pm 0.32 ; \\
\text { Valine: } 191.49 \pm \\
0.74\end{array}$ & $\begin{array}{l}\text { Leucine: } 95.42 \pm \\
0.54 ; \text { Isoleucine: } \\
51.30 \pm 0.27 \\
\text { Valine: } 177.02 \pm \\
0.61\end{array}$ & 8 \\
\hline $\begin{array}{l}\text { Rahimi et } \\
\text { al.(16) }\end{array}$ & 2017 & Iran & Asian & 31 & 25 & $\begin{array}{l}\text { Cases: } 32.65 \pm 5.56 \\
\text { Controls: } 29.46 \pm \\
5.45\end{array}$ & $\begin{array}{l}\text { Cases: } 30.43 \pm \\
\text { 3.50; Controls: } 28.51 \\
\pm 3.66\end{array}$ & $\begin{array}{l}\text { DM diagnosis can be } \\
\text { accomplished with either of two } \\
\text { strategies: } 1 \text { " "One--step" 75-g } \\
\text { OGTT or; } 2 \text { "Two-step" approach } \\
\text { with a 50-g (non-fasting) screen } \\
\text { followed by a 100-g OGTT for } \\
\text { those who screen positive. }\end{array}$ & $\begin{array}{l}\text { Leucine: } 454.02 \pm \\
826.43 \text {; Isoleucine: } \\
55.38 \pm 18.94 ; \\
\text { Valine: } 168.99 \pm \\
63.38\end{array}$ & $\begin{array}{l}\text { Leucine: } 82.04 \pm \\
35.36 ; \text {; soleucine: } \\
52.01 \pm 20.91 ; \\
\text { Valine: } 140.77 \pm \\
51.22\end{array}$ & 8 \\
\hline $\begin{array}{l}\text { Park et al. } \\
(15)\end{array}$ & 2015 & Korea & Asian & 64 & 25 & $\begin{array}{l}\text { Cases: } 33.70 \pm 4.10 \\
\text { Controls: } 33.30 \pm \\
3.80\end{array}$ & $\begin{array}{l}\text { Cases: } 26.90 \pm \\
3.40 ; \text { Controls: } \\
23.50 \pm 2.00\end{array}$ & $\begin{array}{l}\text { GDM screening was performed at } \\
\text { weeks } 2428 \text { of gestation using a } \\
\text { universal two-step GDM } \\
\text { screening program with a } \\
\text { 50-gram glucose challenge test. } \\
\text { Testing positive were } \\
\text { administered a 100-gram, 3-h oral } \\
\text { glucose tolerance test (OGTT). } \\
\text { GDM was identified according to } \\
\text { the Carpenter Coustan criteria. }\end{array}$ & $\begin{array}{l}\text { Isoleucine: } 97.9 \pm \\
\text { 14.4; Valine: } 124.00 \\
\pm 30.00\end{array}$ & $\begin{array}{l}\text { Isoleucine: } 63.20 \pm \\
9.50 \text {; Valine: } 97.50 \\
\pm 12.60\end{array}$ & 9 \\
\hline $\begin{array}{l}\text { Pappa et al. } \\
\text { (18) }\end{array}$ & 2007 & Greece & Caucasiar & 25 & 46 & $\begin{array}{l}\text { Cases: } 27.84 \pm 5.14 \\
\text { Controls: } 27.85 \pm \\
4.99\end{array}$ & $\begin{array}{l}\text { Cases: } 27.32 \pm 5.56 \\
\text { Controls: } 23.49 \pm \\
5.24\end{array}$ & $\begin{array}{l}\text { Pregnant women were screened } \\
\text { for gestational diabetes at the } \\
\text { 26th week, according to the } \\
\text { criteria established by the Fourth } \\
\text { International Gestational } \\
\text { Diabetes Workshop. }\end{array}$ & $\begin{array}{l}\text { Leucine: } 113.94 \pm \\
\text { 28.91; Isoleucine: } \\
65.65 \pm 18.92 ; \\
\text { Valine: } 199.18 \pm \\
47.73\end{array}$ & $\begin{array}{l}\text { Leucine: } 111.76 \pm \\
\text { 30.32; Isoleucine: } \\
64.24 \pm 16.92 ; \\
\text { Valine: } 195.54 \pm \\
48.89\end{array}$ & 9 \\
\hline $\begin{array}{l}\text { Cetin et al. } \\
(19)\end{array}$ & 2005 & Italy & Caucasian & 17 & 16 & $\begin{array}{l}\text { Cases: } 38.60 \pm \\
0.30 ; \text { Controls: } \\
38.30 \pm 0.20\end{array}$ & $\begin{array}{l}\text { Cases: } 28.00 \pm \\
1.60 ; \text { Controls: } 24.50 \\
\pm 2.20\end{array}$ & $\begin{array}{l}\text { GDM was diagnosed with the } \\
\text { presence of a } 100 \text { g oral glucose } \\
\text { tolerance test with } 2 \text { or more } \\
\text { values over the ranges } \\
\text { established by Carpenter and } \\
\text { Coustan. }\end{array}$ & $\begin{array}{l}\text { Leucine: } 79.60 \pm \\
4.60 ; \text {;soleucine: } \\
44.40 \pm 2.80 \\
\text { Valine: } 136.10 \pm \\
8.10\end{array}$ & $\begin{array}{l}\text { Leucine: } 80.70 \pm \\
4.80 ; \text { Isoleucine: } \\
43.20 \pm 2.80 \\
\text { Valine: } 141.40 \pm \\
8.60\end{array}$ & 8 \\
\hline $\begin{array}{l}\text { Fitch and } \\
\text { King }(13)\end{array}$ & 1987 & USA & Caucasiar & 2 & 8 & $\begin{array}{l}\text { Cases: } 28.50 \pm \\
7.80 ; \text { Controls: } \\
26.80 \pm 7.40\end{array}$ & $\mathrm{NA}$ & $\mathrm{NA}$ & $\begin{array}{l}\text { Leucine: } 67.60 \pm \\
\text { 17.70; Isoleucine: } \\
37.70 \pm 10.80 ; \\
\text { Valine: } 141.10 \pm \\
32.00\end{array}$ & $\begin{array}{l}\text { Leucine: } 73.10 \pm \\
11.40 \text {; Isoleucine: } \\
40.20 \pm 7.80 \\
\text { Valine: } 142.90 \pm \\
17.20\end{array}$ & 7 \\
\hline $\begin{array}{l}\text { Metzger et } \\
\text { al.(14) }\end{array}$ & & & & 6 & 8 & $\begin{array}{l}\text { Cases: } 27.70 \pm 2.40 \\
\text { Controls: } 23.40 \pm \\
1.70\end{array}$ & $\mathrm{NA}$ & $\begin{array}{l}\text { We diagnosis GDM with a 100-g } \\
\text { oral glucose tolerance test using } \\
\text { the criteria of O'Sullivan and } \\
\text { Mahan. }\end{array}$ & $\begin{array}{l}\text { Leucine: } 117.00 \pm \\
4.00 ; \text { Isoleucine: } \\
64.00 \pm 3.00 \\
\text { Valine: } 201.00 \pm \\
10.00\end{array}$ & $\begin{array}{l}\text { Leucine: } 86.00 \pm \\
\text { 5.00; Isoleucine: } \\
47.00 \pm 3.00 \\
\text { Valine: } 159.00 \pm \\
8.00\end{array}$ & 7 \\
\hline
\end{tabular}

Abbreviations: BCAAs, branched-chain amino acids; BMI, body mass index; NA, not available; NOS, Newcastle-Ottawa-Scale; SD, standard deviation; GDM, gestational diabetes mellitus.

${ }^{\mathrm{a}}$ Values are expressed as mean $\pm \mathrm{SD}$.

trations. The measurement values of BCAAs were significantly different between the GDM group and the control group, and these differences were not found in the BMI $<28 \mathrm{~kg} / \mathrm{m}^{2}$ group. Differently, the latest research manifested that serum BCAAs levels were significantly higher in T2DM than those in controls in Jordan independent of age and BMI (37). However, Roy et al.'s study (17) yielded BCAA concentrations combined with BMI and age may improve the diagnostic ability accuracy of GDM. Additionally, the researchers found both Asian group and Caucasian group exhibited higher plasma BCAAs concentrations in patients, especially in Caucasian GDM patients. Tillin et al. (36) reported all three individual serum BCAA concentrations were significantly higher in South Asian males. They also found that ethnic differences in three individual serum BCAA concentrations compared with Caucasian subgroup still remained in spite of the South Asian subgroup (36). The current study also showed that there were significant differences in all three individuals BCAAs between the GDM group and the control group in the publication year of $\geq$ 2007 study, and these differences were not found in the study published in the year $<2007$.

\subsection{Strengths and Limitations}

Some strengths could be emphasized in the current study. Firstly, the researchers conducted a quantitative analysis for the first time to estimate the association between plasma BCAAs concentrations and DM. Secondly, comprehensive methods including strict literature screening and quality evaluation process were utilized to reduce bias. Thirdly, stratified analysis showed that some variables (age, BMI, publication year and ethnicity) could be 


\begin{tabular}{|c|c|c|c|c|c|c|}
\hline BCAAs & $\mathbf{N}$ & $\operatorname{SMD}(95 \% \mathrm{CI})$ & $\mathbf{P}($ SMD $)$ & $\mathbf{I}^{2}(\%)$ & $\mathbf{P}(\mathbf{H})$ & $\mathbf{P}(\mathbf{S})$ \\
\hline Leucine & 7 & $3.76(1.70,5.82)$ & $<0.001$ & 97.2 & $<0.001$ & \\
\hline Age, y & & & & & & 0.07 \\
\hline$<30$ & 3 & $1.70(-1.04,4.43)$ & 0.224 & 90.2 & $<0.001$ & \\
\hline$\geq 30$ & 4 & $5.73(2.01,9.46)$ & 0.003 & 98.4 & $<0.001$ & \\
\hline $\mathrm{BMI}, \mathrm{kg} / \mathrm{m}^{2}$ & & & & & & 0.25 \\
\hline$<28$ & 2 & $11.68(-11.18,34.54)$ & 0.317 & 99.5 & $<0.001$ & \\
\hline$\geq 28$ & 2 & $0.21(-0.61,1.03)$ & 0.611 & 71.8 & 0.060 & \\
\hline Ethnicity & & & & & & - \\
\hline Unclear & 3 & $2.51(-0.64,5.67)$ & 0.118 & 89.5 & $<0.001$ & \\
\hline Caucasian & 6 & $4.68(1.79,7.57)$ & 0.002 & 97.7 & $<0.001$ & \\
\hline Publication year & & & & & & 0.02 \\
\hline$<2007$ & 4 & $1.63(-0.48,3.75)$ & 0.129 & 89.6 & $<0.001$ & \\
\hline$\geq 2007$ & 3 & $7.03(2.92,11.4)$ & 0.001 & 98.9 & $<0.001$ & \\
\hline Isoleucine & 8 & $3.15(1.42,4.87)$ & $<0.001$ & 97.1 & $<0.001$ & \\
\hline Age, $y$ & & & & & & 0.12 \\
\hline$<30$ & 3 & $1.52(-1.00,4.04)$ & 0.238 & 89.4 & $<0.001$ & \\
\hline$\geq 30$ & 5 & $4.19(1.60,6.77)$ & 0.002 & 98.1 & $<0.001$ & \\
\hline $\mathrm{BMI}, \mathrm{kg} / \mathrm{m}^{2}$ & & & & & & 0.01 \\
\hline$<28$ & 3 & $5.32(1.89,10.76)$ & 0.005 & 99.0 & $<0.001$ & \\
\hline$\geq 28$ & 2 & $0.27(-0.15,0.68)$ & 0.215 & 0 & 0.560 & \\
\hline Ethnicity & & & & & & 0.17 \\
\hline Unclear & 3 & $2.14(-0.48,5.31)$ & 0.102 & 88.1 & $<0.001$ & \\
\hline Asian & 2 & $1.39(-1.01,3.80)$ & 0.256 & 97.2 & $<0.001$ & \\
\hline Caucasian & 6 & $4.00(1.23,6.77)$ & 0.005 & 97.6 & $<0.001$ & \\
\hline Publication year & & & & & & 0.09 \\
\hline$<2007$ & 4 & $1.77(-0.09,3.62)$ & 0.062 & 86.5 & $<0.001$ & \\
\hline$\geq 2007$ & 4 & $4.63(1.71,7.36)$ & 0.002 & 98.6 & $<0.001$ & \\
\hline Valine & 8 & $2.77(1.21,4.32)$ & 0.001 & 96.8 & $<0.001$ & \\
\hline Age, $y$ & & & & & & 0.11 \\
\hline$<30$ & 3 & $1.36(-0.92,3.64)$ & 0.242 & 88.3 & $<0.001$ & \\
\hline$\geq 30$ & 5 & $3.87(1.49,6.24)$ & 0.001 & 98.0 & $<0.001$ & \\
\hline $\mathrm{BMI}, \mathrm{kg} / \mathrm{m}^{2}$ & & & & & & 0.003 \\
\hline$<28$ & 3 & $6.63(2.75,10.51)$ & 0.001 & 98.9 & $<0.001$ & \\
\hline$\geq 28$ & 2 & $-0.05(-1.15,1.04)$ & 0.926 & 83.9 & 0.013 & \\
\hline Ethnicity & & & & & & 0.03 \\
\hline Unclear & 3 & $1.86(-0.42,4.15)$ & 0.110 & 84.1 & 0.002 & \\
\hline Asian & 2 & $0.76(0.25,1.27)$ & 0.004 & 49.9 & 0.158 & \\
\hline Caucasian & 6 & $4.01(1.24,6.79)$ & 0.005 & 97.7 & $<0.001$ & \\
\hline Publication year & & & & & & 0.02 \\
\hline$<2007$ & 4 & $1.15(-0.71,3.01)$ & 0.224 & 88.6 & $<0.001$ & \\
\hline$\geq 2007$ & 4 & $4.57(2.07,7.07)$ & $<0.001$ & 98.4 & $<0.001$ & \\
\hline
\end{tabular}

Abbreviations: CIs, confidence intervals; $\mathrm{N}$, number of included studies; $\mathrm{P}(\mathrm{H})$, P for heterogeneity; $\mathrm{P}(\mathrm{S})$, P for subgroup differences; SMD, standardized mean differences.

potential sources of heterogeneity.

However, limitations do exist in the present study. Firstly, only seven articles (including eight studies) were included. Additionally, the number of the included articles in some subgroups is relatively small. Secondly, some included studies that covered a smaller number of subjects.
Thirdly, due to the limited number of included articles, the researchers did not discuss the association between total BCAAs and GDM. Fourth, there may be potential publication bias. 


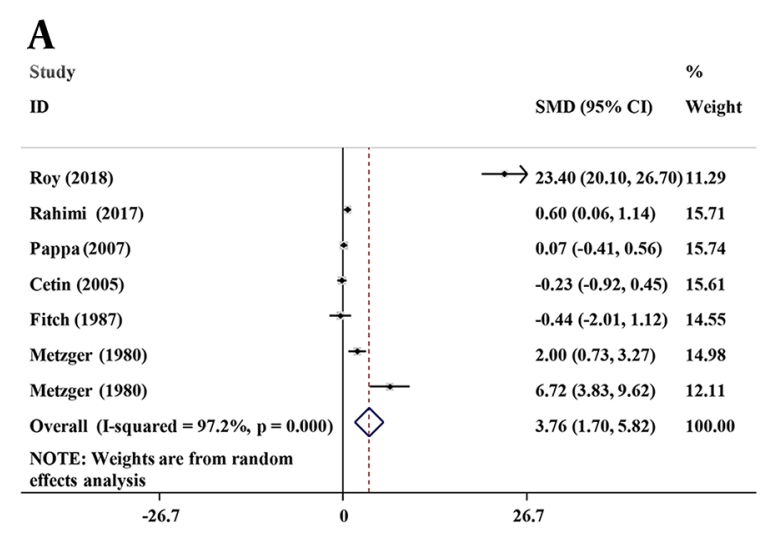

B

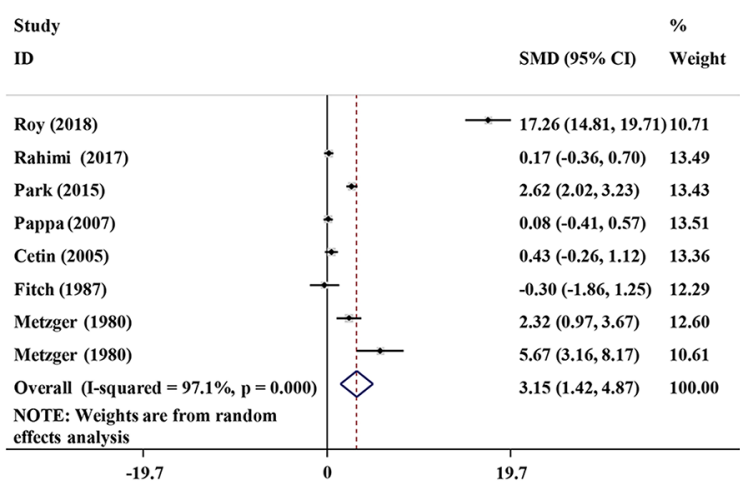

C
Study

ID

\section{Roy (2018)}

Rahimi (2017)

Park (2015)

Pappa (2007)

Cetin (2005)

Fitch (1987)

Metzger (1980)

Metzger (1980)

Overall (I-squared $=96.8 \%, p=0.000$ )

NOTE: Weights are from random effects analysis
$\%$

$21.34(18.33,24.35) 9.15$ $0.48(-0.05,1.02) \quad 13.69$ $1.00(0.52,1.49) \quad 13.73$ $0.08(-0.41,0.56) \quad 13.73$ $-0.64(-1.34,0.07) \quad 13.54$ $-0.09(-1.64,1.46) \quad 12.23$ $1.37(0.23,2.51) \quad 12.95$ $4.73(2.56,6.89) \quad 10.97$ $2.77(1.21,4.32) \quad 100.00$
Figure 2. Forest plot of the plasma branched-chain amino acids concentrations levels in gestational diabetes mellitus. A, leucine; $\mathrm{B}$, isoleucine; $\mathrm{C}$, valine. Abbreviations: SMD, standardized mean difference; $\mathrm{CI}$, confidence interval.

\section{Conclusions}

In summary, this study demonstrates that BCAAs are associated with GDM risk and might be potential biomarkers for GDM. Well-designed and large-scale prospective studies are required to further confirm the validity of the results.
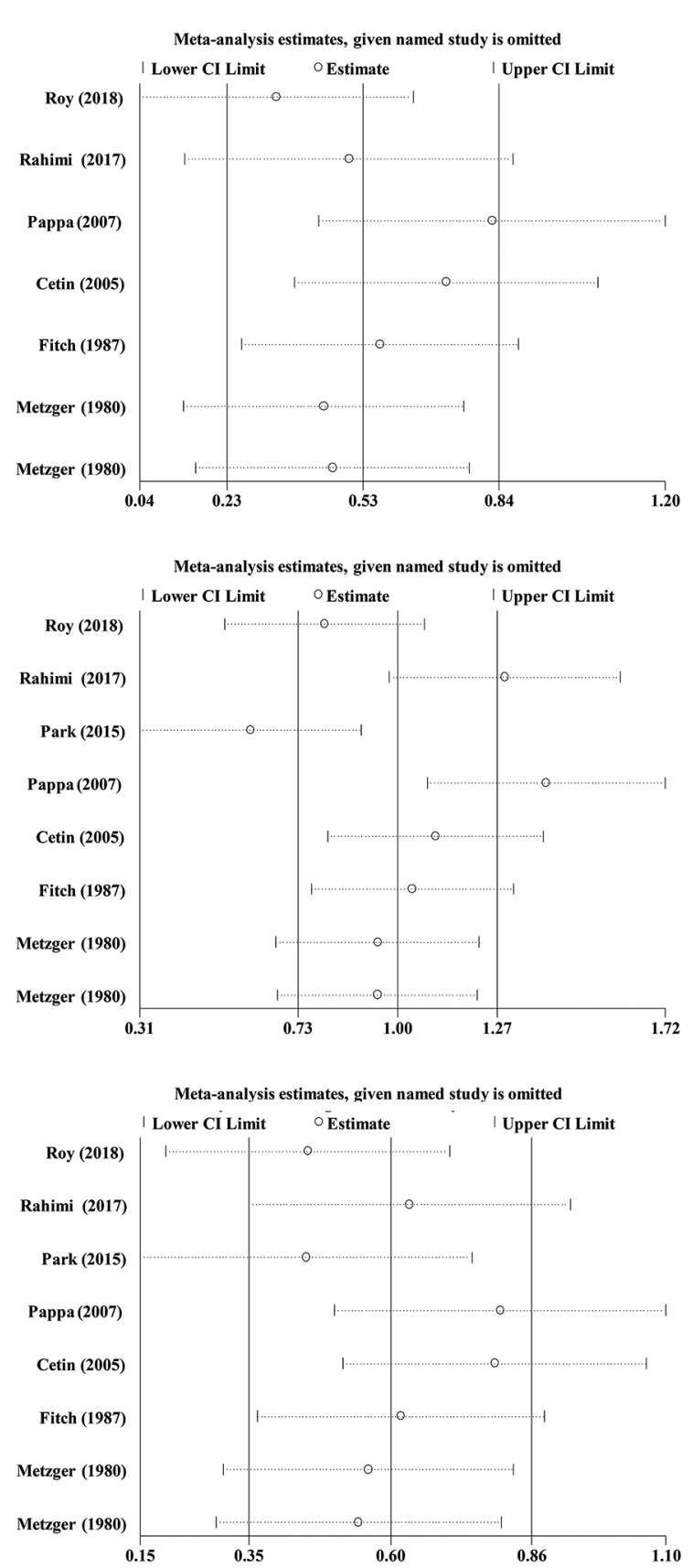

Figure 3. Plot of sensitivity analyses. A, leucine; B, isoleucine; C, valine.

\section{Footnotes}

Authors' Contribution: Minglong Li: Study conception, design, and manuscript revision for important intellectual content. Liang Zhao and Meng Wang: Data analysis, interpretation, and manuscript draft. Jun Li, Ye Bi and Jie Yang: Data acquisition, literature search and statistical analysis. 
Minglong Li: Agreement to be accountable for all aspects of the work related to the accuracy or integrity of any part of the work.

Conflicts of Interests: The authors report no conflicts of interest.

Funding/Support: This study was supported by Key Research and Development Plan of Shandong Province (Grant No.: 2016GSF201016).

\section{References}

1. Hu FB. Globalization of diabetes: The role of diet, lifestyle, and genes. Diabetes Care. 2011;34(6):1249-57. doi: 10.2337/dc11-0442. [PubMed: 21617109]. [PubMed Central: PMC3114340].

2. Yang L, Shao J, Bian Y, Wu H, Shi L, Zeng L, et al. Prevalence of type 2 diabetes mellitus among inland residents in China (2000-2014): A meta-analysis.JDiabetes Investig. 2016;7(6):845-52. doi:10.1111/jdi.12514. [PubMed: 27181391]. [PubMed Central: PMC5089946].

3. Shen Y, Cai R, Sun J, Dong X, Huang R, Tian S, et al. Diabetes mellitus as a risk factor for incident chronic kidney disease and end-stage renal disease in women compared with men: A systematic review and meta-analysis. Endocrine. 2017;55(1):66-76. doi: 10.1007/s12020016-1014-6. [PubMed: 27477292].

4. Zhang P, Zhang X, Brown J, Vistisen D, Sicree R, Shaw J, et al. Global healthcare expenditure on diabetes for 2010 and 2030. Diabetes Res Clin Pract. 2010;87(3):293-301. doi: 10.1016/j.diabres.2010.01.026. [PubMed: 20171754].

5. American Diabetes Association. 2. Classification and diagnosis of diabetes: Standards of medical care in diabetes-2019. Diabetes Care. 2019;42(Suppl 1):S13-28. doi: 10.2337/dc19-S002. [PubMed: 30559228].

6. McGrogan A, Snowball J, de Vries CS. Pregnancy losses in women with type 1 or type 2 diabetes in the UK: An investigation using primary care records.DiabetMed.2014;31(3):357-65.doi:10.1111/dme.12332.[PubMed: 24111989].

7. Kaasenbrood L, Poulter NR, Sever PS, Colhoun HM, Livingstone SI, Boekholdt SM, et al. Development and validation of a model to predict absolute vascular risk reduction by moderate-intensity statin therapy in individual patients with type 2 diabetes mellitus: The anglo scandinavian cardiac outcomes trial, antihypertensive and lipid-lowering treatment to prevent heart attack trial, and collaborative atorvastatin diabetes study. Circ Cardiovasc Qual Outcomes. 2016;9(3):213-21. doi: 10.1161/CIRCOUTCOMES.115.001980. [PubMed: 27174798].

8. Bak E, Marcisz C, Krzeminska S, Dobrzyn-Matusiak D, Foltyn A, Drosdzol-Cop A. Relationships of sexual dysfunction with depression and acceptance of illness in women and men with type 2 diabetes mellitus. Int J Environ Res Public Health. 2017;14(9). doi: 10.3390/ijerph14091073. [PubMed: 28926936]. [PubMed Central: PMC5615610]

9. Wu G. Amino acids: Metabolism, functions, and nutrition. Amino Acids. 2009;37(1):1-17. doi: 10.1007/s00726-009-0269-0. [PubMed: 19301095].

10. Bhattacharya S, Granger CB, Craig D, Haynes C, Bain J, Stevens $\mathrm{RD}$, et al. Validation of the association between a branched chain amino acid metabolite profile and extremes of coronary artery disease in patients referred for cardiac catheterization. Atherosclerosis. 2014;232(1):191-6. doi: 10.1016/j.atherosclerosis.2013.10.036. [PubMed: 24401236]. [PubMed Central: PMC4784695].

11. Lynch CJ, Adams SH. Branched-chain amino acids in metabolic signalling and insulin resistance. Nat Rev Endocrinol. 2014;10(12):723-36. doi: 10.1038/nrendo.2014.171. [PubMed: 25287287]. [PubMed Central: PMC4424797].
12. Batch BC, Hyland K, Svetkey LP. Branch chain amino acids: Biomarkers of health and disease. Curr Opin Clin Nutr Metab Care. 2014;17(1):86-9. doi: 10.1097/MCO.0000000000000010. [PubMed: 24310057].

13. Fitch WL, King JC. Plasma amino acid, glucose, and insulin responses to moderate-protein and high-protein test meals in pregnant, nonpregnant, and gestational diabetic women. Am J Clin Nutr. 1987;46(2):243-9. doi: 10.1093/ajcn/46.2.243. [PubMed: 3303897].

14. Metzger BE, Phelps RL, Freinkel N, Navickas IA. Effects of gestational diabetes on diurnal profiles of plasma glucose, lipids, and individual amino acids. Diabetes Care. 1980;3(3):402-9. doi: 10.2337/diacare.3.3.402. [PubMed: 7190092].

15. Park S, Park JY, Lee JH, Kim SH. Plasma levels of lysine, tyrosine, and valine during pregnancy are independent risk factors of insulin resistance and gestational diabetes. Metab Syndr Relat Disord. 2015;13(2):64-70. doi: 10.1089/met.2014.0113. [PubMed: 25419905].

16. Rahimi N, Razi F, Nasli-Esfahani E, Qorbani M, Shirzad N, Larijani B. Amino acid profiling in the gestational diabetes mellitus. J Diabetes Metab Disord. 2017;16:13. doi: 10.1186/s40200-016-0283-1. [PubMed: 28367428]. [PubMed Central: PMC5374565].

17. Roy C, Tremblay PY, Anassour-Laouan-Sidi E, Lucas M, Forest JC, Giguere $\mathrm{Y}$, et al. Risk of gestational diabetes mellitus in relation to plasma concentrations of amino acids and acylcarnitines: A nested case-control study. Diabetes Res Clin Pract. 2018;140:183-90. doi: 10.1016/j.diabres.2018.03.058. [PubMed: 29626588]

18. Pappa KI, Vlachos G, Theodora M, Roubelaki M, Angelidou K, Antsaklis $\mathrm{A}$. Intermediate metabolism in association with the amino acid profile during the third trimester of normal pregnancy and dietcontrolled gestational diabetes. Am JObstet Gynecol. 2007;196(1):65 e15. doi: 10.1016/j.ajog.2006.06.094. [PubMed:17240238].

19. Cetin I, de Santis MS, Taricco E, Radaelli T, Teng C, Ronzoni S, et al. Maternal and fetal amino acid concentrations in normal pregnancies and in pregnancies with gestational diabetes mellitus. Am J Obstet Gynecol. 2005;192(2):610-7. doi: 10.1016/j.ajog.2004.08.011. [PubMed: 15696011].

20. Moher D, Liberati A, Tetzlaff J, Altman DG, Prisma Group . Preferred reporting items for systematic reviews and meta-analyses: the PRISMA statement. J Clin Epidemiol. 2009;62(10):1006-12. doi: 10.1016/j.jclinepi.2009.06.005. [PubMed: 19631508].

21. Deeks JJ, Dinnes J, D’Amico R, Sowden AJ, Sakarovitch C, Song F, et al Evaluating non-randomised intervention studies. Health Technol Assess. 2003;7(27):iii-X. 1-173. [PubMed: 14499048].

22. Margulis AV, Pladevall M, Riera-Guardia N, Varas-Lorenzo C, Hazell L, Berkman ND, et al. Quality assessment of observational studies in a drug-safety systematic review, comparison of two tools: The Newcastle-Ottawa Scale and the RTI item bank. Clin Epidemiol. 2014;6:359-68. doi: 10.2147/CLEP.S66677. [PubMed: 25336990]. [PubMed Central: PMC4199858].

23. Higgins JP, Thompson SG. Quantifying heterogeneity in a metaanalysis. Stat Med. 2002;21(11):1539-58. doi:10.1002/sim.1186. [PubMed: 12111919].

24. Egger M, Davey Smith G, Schneider M, Minder C. Bias in metaanalysis detected by a simple, graphical test. BMJ.1997;315(7109):62934. doi: 10.1136/bmj.315.7109.629. [PubMed: 9310563]. [PubMed Central: PMC2127453].

25. Bloomgarden Z. Diabetes and branched-chain amino acids: What is the link? J Diabetes. 2018;10(5):350-2. doi: 10.1111/1753-0407.12645. [PubMed: 29369529].

26. Giesbertz P, Daniel H. Branched-chain amino acids as biomarkers in diabetes. Curr Opin Clin Nutr Metab Care. 2016;19(1):48-54. doi: 10.1097/MCO.0000000000000235. [PubMed: 26485337].

27. Nie C, He T, Zhang W, Zhang G, Ma X. Branched chain amino acids: Beyond nutrition metabolism. Int J Mol Sci. 2018;19(4). doi: 10.3390/ijms19040954. [PubMed: 29570613]. [PubMed Central: PMC5979320].

28. Chorell E, Hall UA, Gustavsson C, Berntorp K, Puhkala J, Luoto R, et al. Pregnancy to postpartum transition of serum metabolites 
in women with gestational diabetes. Metabolism. 2017;72:27-36. doi: 10.1016/j.metabol.2016.12.018. [PubMed: 28641781].

29. Tobias DK, Clish C, Mora S, Li J, Liang L, Hu FB, et al. Dietary intakes and circulating concentrations of branched-chain amino acids in relation to incident type 2 diabetes risk among high-risk women with a history of gestational diabetes mellitus. Clin Chem. 2018;64(8):120310. doi: 10.1373/clinchem.2017.285841. [PubMed: 29945965]. [PubMed Central: PMC6434682]

30. Holecek M. Branched-chain amino acids in health and disease: metabolism, alterations in blood plasma, and as supplements. Nutr Metab (Lond). 2018;15:33. doi: 10.1186/s12986-018-0271-1. [PubMed: 29755574]. [PubMed Central: PMC5934885].

31. Tobias DK, Lawler PR, Harada PH, Demler OV, Ridker PM, Manson JE, et al. Circulating branched-chain amino acids and incident cardiovascular disease in a prospective cohort of US women. Circ Genom Precis Med.2018;11(4). e002157. doi:10.1161/CIRCGEN.118.002157. [PubMed: 29572205]. [PubMed Central: PMC5880282].

32. Lee SG, Yim YS, Lee YH, Lee BW, Kim HS, Kim KS, et al. Fasting serum amino acids concentration is associated with insulin resistance and pro-inflammatory cytokines. Diabetes Res Clin Pract. 2018;140:107-17. doi: 10.1016/j.diabres.2018.03.028. [PubMed: 29601913].

33. O'Connell TM. The complex role of branched chain amino acids in diabetes and cancer. Metabolites. 2013;3(4):931-45. doi: 10.3390/metabo3040931. [PubMed: 24958258]. [PubMed Central: PMC3937834].

34. Newgard CB, An J, Bain JR, Muehlbauer MJ, Stevens RD, Lien LF, et al.
A branched-chain amino acid-related metabolic signature that differentiates obese and lean humans and contributes to insulin resistance. Cell Metab. 2009;9(4):311-26. doi: 10.1016/j.cmet.2009.02.002. [PubMed: 19356713]. [PubMed Central: PMC3640280].

35. Jainandunsing S, Wattimena JL, Verhoeven AJ, Langendonk JG, Rietveld T, Isaacs AJ, et al. Discriminative ability of plasma branchedchain amino acid levels for glucose intolerance in families at risk for type 2 diabetes. Metab Syndr Relat Disord. 2016;14(3):175-81. doi: 10.1089/met.2015.0102. [PubMed: 26653072].

36. Tillin T, Hughes AD, Wang Q, Wurtz P, Ala-Korpela M, Sattar N, et al. Diabetes risk and amino acid profiles: Cross-sectional and prospective analyses of ethnicity, amino acids and diabetes in a South Asian and European cohort from the SABRE (Southall And Brent REvisited) Study. Diabetologia. 2015;58(5):968-79. doi: 10.1007/s00125-015-3517-8. [PubMed: 25693751]. [PubMed Central: PMC4392114].

37. Alfaqih MA, Abu-Khdair Z, Saadeh R, Saadeh N, Al-Dwairi A, Al-Shboul O. Serum branched chain amino acids are associated with type 2 diabetes mellitus in Jordan. Korean J Fam Med. 2018;39(5):313-7. doi: 10.4082/kjfm.17.0122. [PubMed: 30060645]. [PubMed Central: PMC6166113].

38. Andersson-Hall U, Gustavsson C, Pedersen A, Malmodin D, Joelsson L, Holmang A. Higher concentrations of BCAAs and 3-HIB are associated with insulin resistance in the transition from gestational diabetes to type 2 diabetes. J Diabetes Res. 2018;2018:4207067. doi: 10.1155/2018/4207067. [PubMed: 29967793]. [PubMed Central: PMC6008749]. 